$\$=$ 国

\title{
The effect of organobentonites from spent bleaching earth (SBE) and commercial bentonite on nanocomposite properties
}

\author{
Tika Paramitha ${ }^{1 *}$, Johnner P. Sitompul ${ }^{2}$, Hyung Woo Lee ${ }^{3}$ \\ ${ }^{1}$ Department of Chemical Engineering, Faculty of Industrial Technology, Institut Teknologi Bandung, \\ Jl. Ganesha 10, Bandung, Indonesia \\ ${ }^{2}$ Center for International Affairs, National Research Foundation of Korea, 25, Heolleungno, Sepcho-gu, Seoul, 06792, Korea
}

\begin{abstract}
This paper concerns on synthesis of nanocomposites consisting of Poly(lactic acid) (PLA) and clays. Two types of clays were regenerated organobentonite and commercial organobentonite. PLA and clays were melt extruded using single-screw extruder. The extruded compound was pelletized, then hot pressed using compression molding machine. Regenerated organobentonite was obtained from regeneration of spent bleaching earth (SBE) using solvent extraction and oxidation method. Afterwards, regenerated SBE modified by organic compound. While, commercial organobentonite was directly modified of commercial bentonite using organic compound. In this study, nanocomposites were prepared with varying compositions of clays from $0 \%$ to $5 \%$ (by weight). Experimental results show that partially exfoliated nanocomposites structure was shown by X-ray diffraction analyses. In addition, the effect of clays on morphology structure, mechanical, barrier, and biodegradable properties were analyzed. The utilization of clays in nanocomposite increases mechanical properties at low clay compositions. Furthermore, PLA-clay nanocomposites show better barrier and biodegradable properties compared to that of the neat PLA.
\end{abstract}

Keywords: Nanocomposite; PLA; Regenerated Organobentonit; Commercial Organobentonite; Extrusion.

\section{Introduction}

There are four processes on the refining industry of crude palm oil (CPO), includes: degumming, neutralization, bleaching, and deodorization. Spent bleaching earth (SBE) is generated during the bleaching step that containing $20-40 \%(\mathrm{w} / \mathrm{w})$ of residual vegetable oil and pigments, oxidation products, free fatty acids (FFA), phosphatides, and trace metals [1] in bentonite. According to Boey [2], in the process of $\mathrm{CPO}$ purification requires $0.5-1.0 \% \mathrm{SBE}$. Until now, only minor part of SBE is utilized, while the rest is disposed of to landfill. The direct disposal may contribute negatively to environmental problems, such as unpleasant odors and fire hazards. In such circumstances, regeneration and utilization of SBE is the object of research.

Regeneration of SBE can be conducted by recovering the oil content. Al-Zahrani [3] was studied that solvent extraction gives a higher yield and better quality of oil. Although there are a large number of studies focusing on regeneration of SBE, the study of utilization of regenerated $\mathrm{SBE}$ as a filler to produce nanocomposite is small. Based on a number of studies, bentonite in which applied to the polymer material to produce nanocomposite can increase in polymer properties. Regenerated SBE as natural clay are hydrophilic, while PLA matrix are hydrophobic. To overcome these problem, intercalation of organic compound on regenerated SBE can change the surface properties from hydrophilic to hydrophobic. Furthermore, intercalation increase basal spacing of layers [4]. In this study, regenerated SBE was used as filler in Poly(lactic acid) (PLA). PLA is promising polymer produced from renewable sources.

Pirani [5] conducted the addition of 1-3\% Cloisite 30B content to PLA matrix result in tougher nanocomposite than the neat PLA. This improvement was not shown for the addition of $4 \%$ and $5 \%$
Cloisite 30B. This may be attributed to the good interfacial adhesion between the Cloisite 30B and the PLA matrix at these lower percentage compositions. Chow [6] demonstrated that PLAOMMT (organo-montmorillonite) nanocomposite showed higher water uptake but lower diffusion coefficient compared to the neat PLA. The increase in moisture content value is attributed to the hydrophilic nature of OMMT's surface.

The main objective of this research was to analyze the effect of chemical modifications of regenerated SBE and commercial bentonite on the final properties of nanocomposites. Specifically, mechanical properties, water absorption properties, and biodegradable properties were studied as a function of clay composition.

\section{Experimental}

\subsection{Materials}

Poly(lactic acid) (PLA), trade name PLA Ingeo 2003D, was supplied from Nature Work, USA. Spent bleaching earth and commercial bentonite was obtained from oil-refining industry (Jakarta, Indonesia). Octadecylamine was supplied by Hebei Nuob Trade Co., Ltd. Technical hexane and sodium hypochlorite $(\mathrm{NaOCl})$ from $\mathrm{PT}$. Brataco Chemica, Bandung, Indonesia. Ethanol and hydrochloric acid from Merck, Germany. Distilled water.

\subsection{Regeneration of spent bleaching earth}

The 25 gram of spent bleaching earth was extracted using $200 \mathrm{~mL}$ of n-hexane at $65^{\circ} \mathrm{C}$ for 5 hours. It was dried at $110^{\circ} \mathrm{C}$ and screened with a sieve of 325 mesh. The 10 gram of the passing part were dispersed in $\mathrm{NaOCl}$ solution at $80-90^{\circ} \mathrm{C}$ for 2 hours. The $\mathrm{NaOCl}$ solution was prepared by dissolving $569.2 \mathrm{~mL}$ of $\mathrm{NaOCl} 1 \mathrm{~N}$ and 
adding water up to $1 \mathrm{~L}$. It was washed with water, dried at $110^{\circ} \mathrm{C}$, screened with a sieve of 325 mesh, and stored in a desiccator (Regenerated SBE).

\subsection{Modification of regenerated SBE and commercial bentonite}

In a container, the 10 gram of regenerated SBE/commercial bentonite was dispersed in $200 \mathrm{~mL}$ of water/ethanol (4/1, v/v) solution at $70^{\circ} \mathrm{C}$ for 2 hours. In another container, Octadecylammonium chloride was prepared by mixing 3.19 grams of octadecylamine and 0.9 $\mathrm{ml}$ of concentrated hydrochloric acid in $100 \mathrm{~mL}$ of water/ethanol $(1 / 1, v / v)$. Both of the solutions were stirred vigorously at $70^{\circ} \mathrm{C}$ for 24 hours. Organobentonites were washed with water several times and dried at $70^{\circ} \mathrm{C}$ for 24 hours.

\subsection{Preparation of nanocomposite}

PLA and filler (two types of clays with composition $0.5 ; 1 ; 3 ; 5 \%$ weight) was mixed using a magnetic stirer. Then, PLA and filler were melt extruded using single-screw extruder at $170^{\circ} \mathrm{C}$. The extruded compound was pelletized and followed by hot pressing to form a film using compression molding machine. The sample was pre-heated for 15 minutes, pressed for 40 minutes, and cooled for 20 minutes using fan.

\subsection{Characterization}

(1) IR spectra were recorded using Bruker Platinum-ATR Spectrometer in the spectral range $4000-500 \mathrm{~cm}^{-1}$ at room temperature. (2) XRD patterns (for clays and nanocomposites) were obtained from a Rigaku Smartlab diffractometer equipped with a $\mathrm{Cu}$ Ka generator $(\mathrm{k}=1.5406 \AA)$ operating at $45 \mathrm{kV}, 30 \mathrm{~mA}$, and at room temperature. (3) The morphology of PLA-clay nanocomposites was characterized using scanning electron microscopy (SEM). Surfaces of nanocomposites were investigated in a Jeol, JSM-6510A (Japan) with the acceleration voltage was $5 \mathrm{kV}$. (4) The specimens for the PLA-clay nanocomposite was carried out according to ASTM D683 type IV. The tensile tests were performed using a universal testing machine RTF-1310, with a load cell of $10 \mathrm{kN}$ and with a crosshead speed of $2 \mathrm{~mm} / \mathrm{min}$. (5) Biodegradability test was carried out with sample dimension of $5 \mathrm{~cm} \times 1 \mathrm{~cm} \times$ thickness. The initial mass of the samples was determined. Samples were buried in compost instrument at $58^{\circ} \mathrm{C}$. The compost was livestock manure. The humidity and type of microorganisms were less in control. (6) Water absorption test was carried out with sample dimension of $5 \mathrm{~cm} \mathrm{x} 1 \mathrm{~cm} \times$ thickness. Samples were dried until constant weight. The tests were conducted by immersing the samples on distilled water at $30^{\circ} \mathrm{C}$ for 7 days. Samples were weighed by removing from water and drying with tissue. The absorption was calculated as:

Percentage of moisture absorption(\%) $=\frac{\mathrm{M}_{\mathrm{t}}-\mathrm{M}_{\mathrm{o}}}{\mathrm{M}_{\mathrm{o}}} \times 100$ (1)

$\mathrm{Mt}$ is the mass of the sample at time $t$ and Mo is the initial mass of the sample (dried).

\section{Results and discussion}

\subsection{Regeneration and characterization of spent bleach- ing earth (SBE)}

Spent bleaching earth is regenerated by two processes. At first process, residual oil was recovered using n-hexane. Second, the extracted SBE was purified by oxidation with $\mathrm{NaOCl}$ solution to take the remaining oil residue. Based on Zimmermann [7], purification (treatment) using $\mathrm{NaOCl}$ solution caused no change in mineral structure. It is proved that no difference in the absorption peak on the FTIR spectra between commercial bentonite and regenerated SBE. Furthermore, oxidation with $\mathrm{NaOCl}$ solution could change the color of SBE from black to brown.

- $\quad$ Spent Bleaching Earth
The characteristic of SBE can be clearly observed from IR spectra in the lattice region of $4000-500 \mathrm{~cm}^{-1}$. In FTIR characterization, organic impurities on SBE can be detected. Oil extracted from SBE contains of $11.5 \%$ free fatty acid and $88.1 \%$ fatty acid [8].

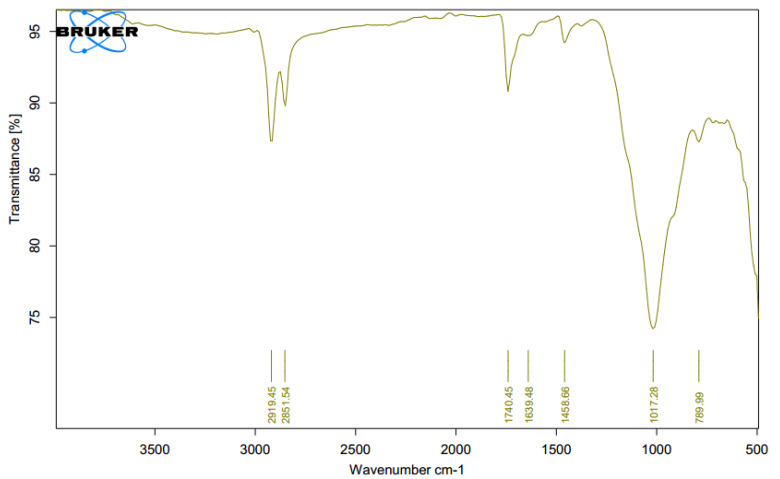

Fig. 1: FTIR Spectra of Spent Bleaching Earth (SBE).

In the FTIR spectra of Figure 1, the peak is absent in the range of $3350-3550 \mathrm{~cm}^{-1}$. However, there is a broad area of $-\mathrm{O}-\mathrm{H}$ bond at the wave number above $3000 \mathrm{~cm}^{-1}$. The peaks at 2851.54 and $2919.45 \mathrm{~cm}^{-1}$ ascribe the presence of $-\mathrm{C}-\mathrm{H}$ bond indicated the carbon chain of oils and free fatty acids. The presence of oil is also shown at the peak of $1740.45 \mathrm{~cm}^{-1}$ indicating the $-\mathrm{C}=\mathrm{O}$ bond in the ester of the oil.

- Regenerated SBE and Commercial Bentonite

FTIR spectra of regenerated SBE and commercial bentonite was demonstrated in Figure 2. It is proven that the oil can be removed from SBE through two regeneration processes. This is shown in Figure 2 with the disappearance of some absorption peaks at the $2850-2930 \mathrm{~cm}^{-1}$ and $1730 \mathrm{~cm}^{-1}$ indicating the disapperance of oil after regeneration with $\mathrm{n}$-hexane and $\mathrm{NaOCl}$ solution.

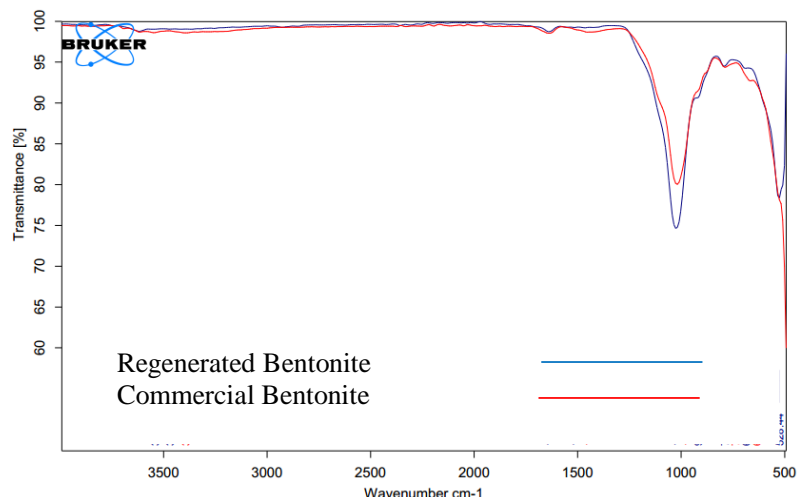

Fig. 2: FTIR Spectra of Regenerated SBE and Commercial Bentonite.

\subsection{Modification and characterization of organ bentonite}

The intercalation of surfactant changes the surface of the clay from hydrophilic to hydrophobic [9] and makes clay compatible with hydrophobic polymers. Moreover, it increases the interlayer distance to allow the polymer enters the interlayer. 


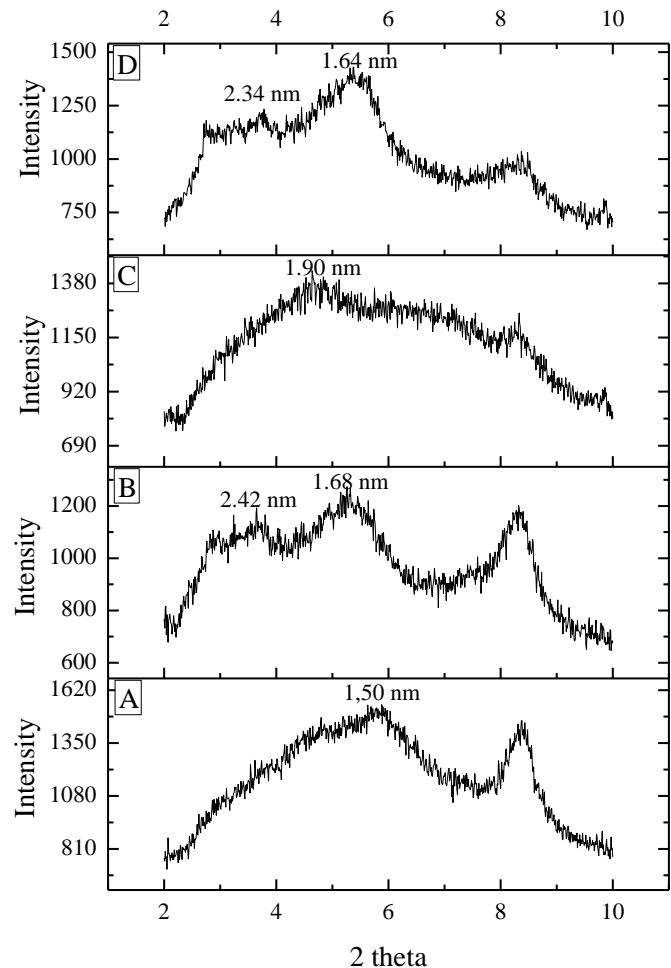

Fig. 3: XRD Patterns for (A) Commercial Bentonite; (B) Commercial Organobentonite; (C) Regenerated SBE; (D) Regenerated Organobentonite.

In Figure 3, two peaks are form at a low diffraction angle. The results indicate that the increase in interlayer distance isn't maximum. The increase occurs not uniformly in commercial organobentonite and regenerated organobentonite. Therefore, there are a very large and a very small interlayer distance of organobentonite. Schematic illustration of the increase in interlayer distance of organobentonite is shown in Figure 4. There are two possibilities of increasing interlayer distance due to modification of clay.
(A)

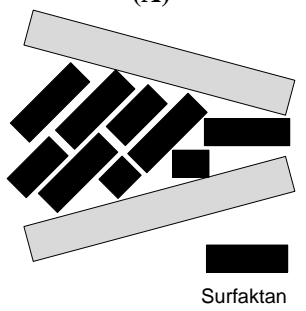

(B)

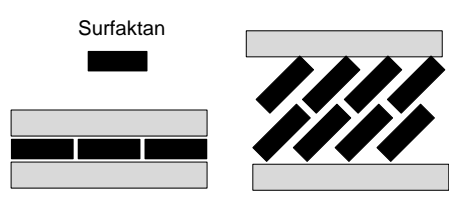

Fig. 4: Schematic Illustration of the Increase in Interlayer Distance.

In Figure 4 (A), the increase in interlayer distance occurs not uniformly between one side of the clay with the other side. On the one side, the increase in interlayer distance is very large. On the other side, the increase in interlayer distance is small. While in Figure 4 (B), the increase in interlayer distance is the same on the two clay sides. Some clay modification increases the interlayer distance is large, and the other clay modifications increase the interlayer distance is very small.

\subsection{Characterization of nanocomposites}

\subsubsection{Nanocomposite structure}

(A)

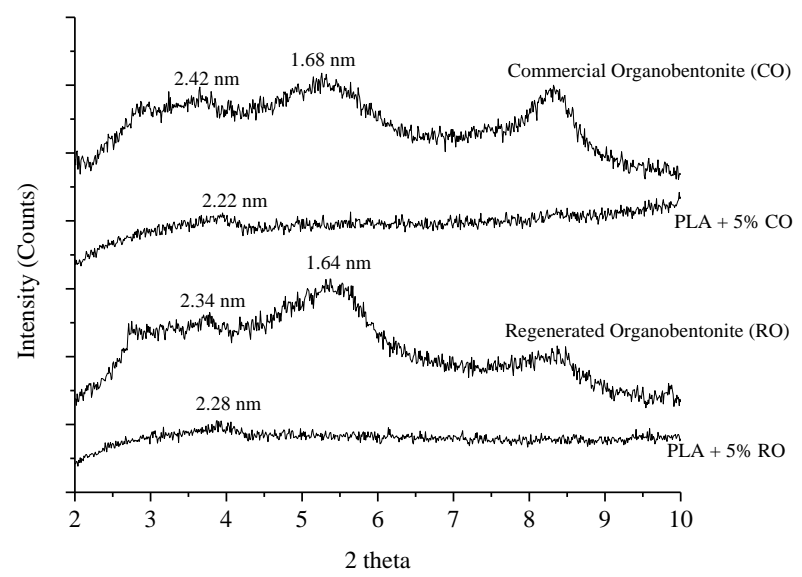

(B)

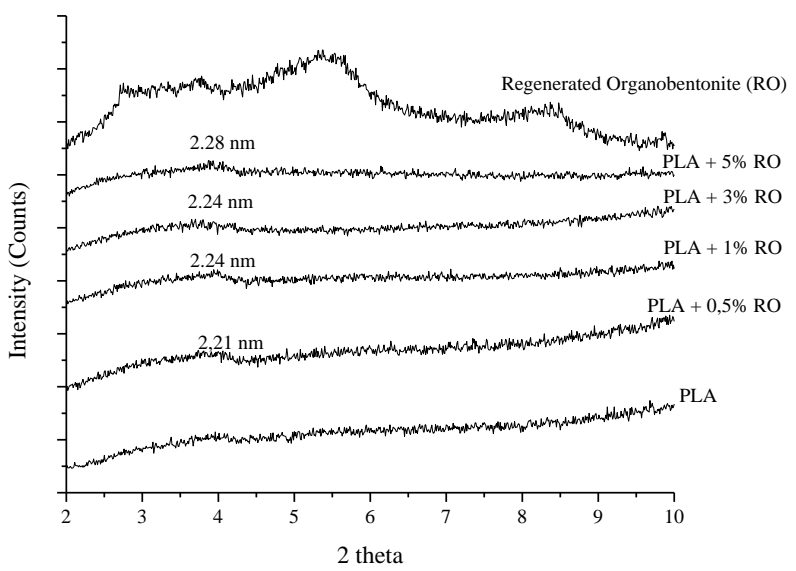

Fig. 5: XRD Pattern for (A) PLA-Commercial Organobentonite and PLARegenerated Organobentonite, (B) PLA-Regenerated Organobentonite with Various Compositions of Regenerated Organobentonite.

Nanocomposite structure was estimated by XRD pattern of PLAcommercial organobentonite and PLA-regenerated organobentonite shown in Figure 5(A). XRD pattern for nanocomposites have a very low intensity peak at the same angle with that of regenerated organobentonite or commercial organobentonite indicates probably the formation of a partially exfoliated structure. These findings are in agreement with those reported by Giannakas [10]. It indicated the dispersion of layered silicate is not uniformly dispersed in the polymer matrix, because the sample residence time in extruder is short. In this study, mixing of PLA and filler using single-screw extruder with length $30 \mathrm{~cm}$.

\subsubsection{Morphology}

The surface morphology of PLA-regenerated organobentonite was studied by Scanning Electron Microscopy (SEM). Based on Fig. 6 (A), it can be seen that the surface of nanocomposite (PLA+0.5\% regenerated organobentonite) is relatively smooth. Nanocomposite has uniform and homogenous dispersion of clay. The effect of the increase of clay composition on surface morphology of nanocomposite shown in Fig. 6 (B). The surface morphology of nanocomposite (PLA+ 5\% wt regenerated SBE) became rough. It is found that some part of nanocomposite was deformed. This induce the formation of aggregation of clays [11]. 
(A)

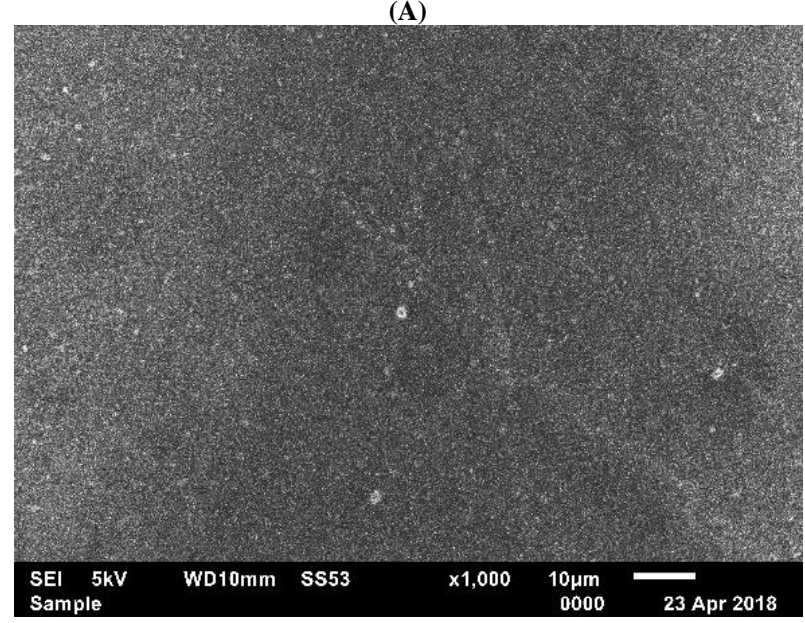

(B)

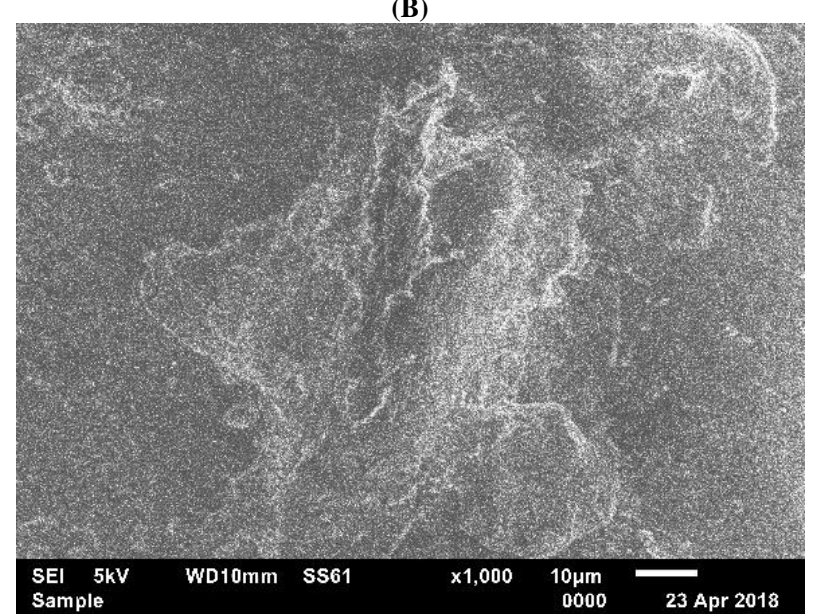

Fig. 6: SEM Micrographs of (A) PLA+0,5\% Regenerated Organobentonite, (B) PLA+5\% Regenerated Organobentonite.

\subsubsection{Mechanical properties}

(A)

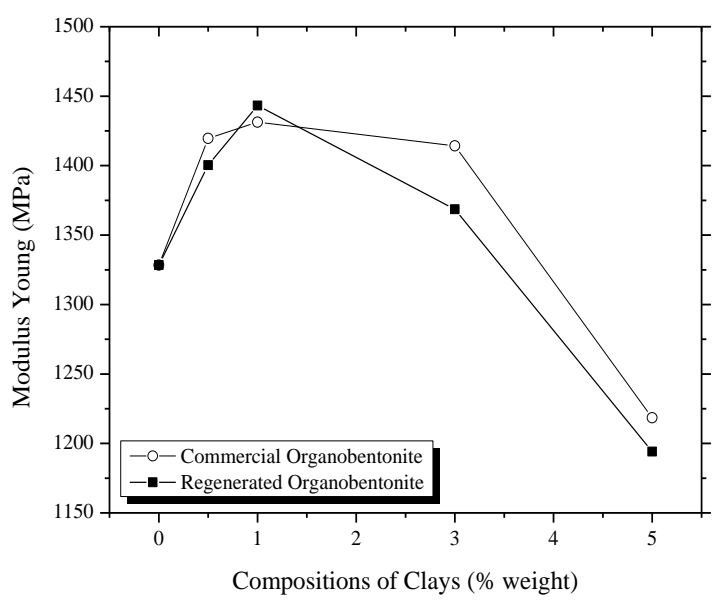

(B)

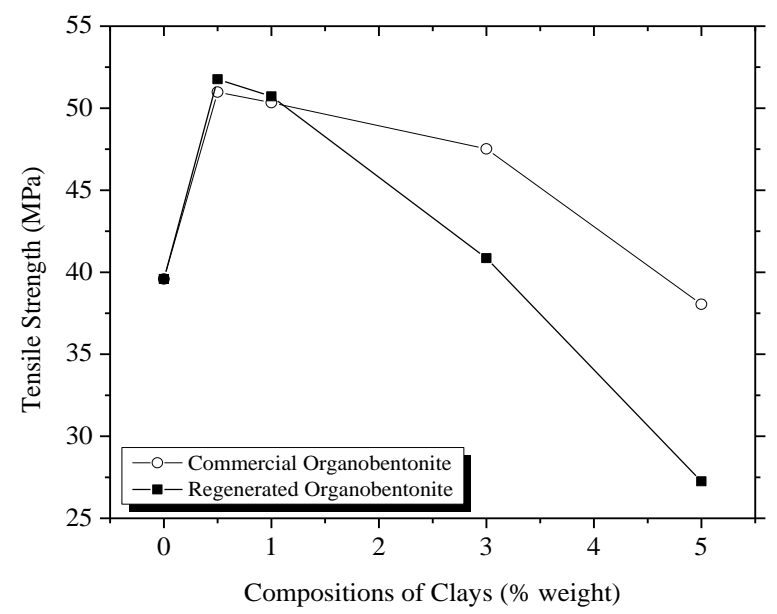

(C)

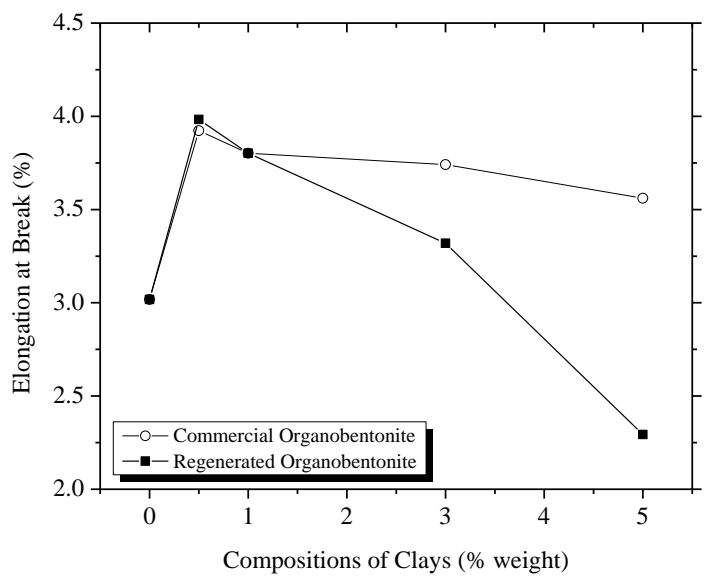

Fig. 7: Mechanical Properties of (A) Modulus Young (B) Tensile Strength (C) Elongation at Break.

In general, modulus young (or tensile modulus) expresses material stiffness at the beginning of the tensile test. Material rigidity increases when the silicate layer is dispersed homogeneously in the polymer matrix. The addition of filler at low composition into the PLA matrix causes the increase in modulus young. This finding was confirmed by Ogah [12] that flexural modulus of the agro fiber/HDPE composites were better than that of the neat HDPE. Modulus young enhancement was associated with better intercalation and exfoliation that resulted in a larger area of the PLA-clay interface [13].

Most interestingly, it can be noticed from Figure 7 that tensile strength of nanocomposite increases with the addition of clay. The highest tensile strength was obtained with the addition $0.5 \%$ both of regenerated organobentonite and commercial organobentonite. The addition of $0.5 \%$ regenerated SBE increase tensile strength about $30.75 \%$ ( $51.76 \mathrm{MPa})$, while the addition of $0.5 \%$ commercial organobentonite increase tensile strength about $28.77 \%(50.98$ $\mathrm{MPa}$ ) in comparison with the tensile strength of neat PLA (39.59 $\mathrm{MPa}$ ). The addition of clays more than $0.5 \%$ started to decrease the tensile strength. The highest decrease in tensile strength occurred in the addition 5\% clays, 27.26 MPa for regenerated organobentonite and 38.04 MPa for commercial organobentonite. The poor dispersion of clays results in the decrease in tensile strength. Clay were dispersed uniformly in the matrix with high aspect ratio at lower loading [14]. While, at high clay composition was obtained agglomeration of clay due to filler-filler interaction. Furthermore, agglomeration of clays leads to local stress concentrations in nanocomposites, which decrease mechanical properties [15]. 
The highest elongation at break was obtained at low clay compositions. The decrease in the elongation at break of nanocomposite can be caused by the decrease in PLA chain mobility due to the addition of clays [16]. The decrease in tensile strength lead to the decrease in the elongation at break. This is assumed due to the partly exfoliated of the layered silicate. Thus, the elongation at break tends to decrease as the interaction between the polymer and the clays becomes stronger [13].

\subsubsection{Water absorption}

Figure 8 depict the effect of compositions of clays on water absorption. From Figure 8, it can be seen that the decrease in water absorption with the addition clays up to $0.5 \%$ for commercial organobentonite and $1 \%$ regenerated organobentonite. At lower clays composition, clays were dispersed uniformly in the nanometer scale in the matrix that can increase the tortuous path of water diffusion into the nanocomposites compared to the neat PLA. On the other hand, the increase in water absorption attributed to the properties of bentonite that has hydrophilic surface [17]

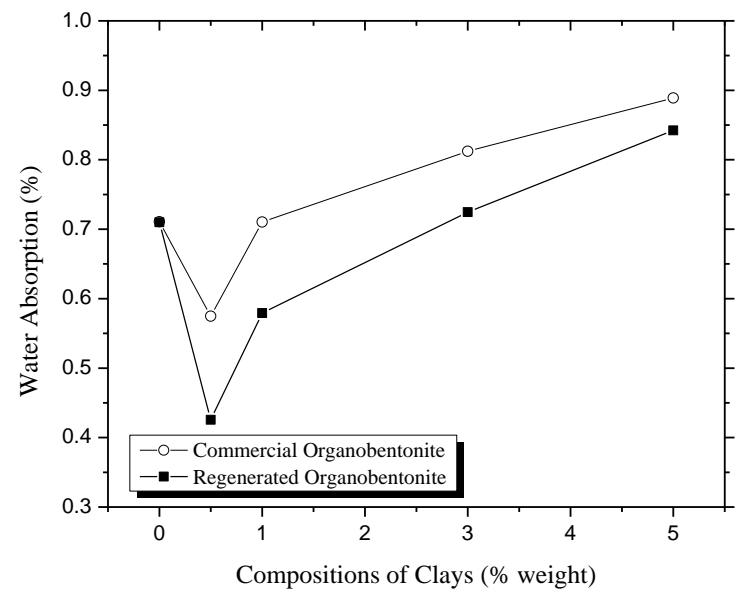

Fig. 8: Water Absorption of PLA-Regenerated Organobentonite and PLACommercial Organobentonite.

\subsubsection{Biodegradability}

In this study, the biodegradation of nanocomposite was conducted on compost instrument [18]. The results were presented in Figure 9.

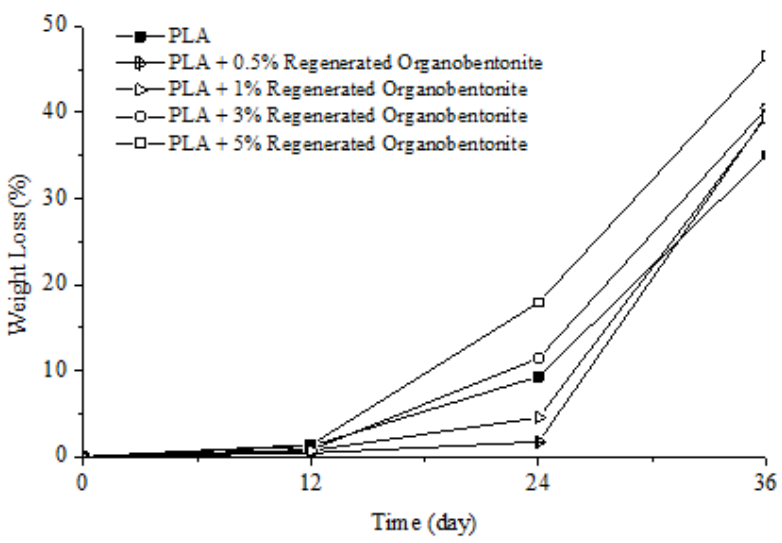

Fig. 9: Percent Weight Loss of PLA and PLA + Regenerated SBE.

The biodegradation rate of PLA $+3 \%$ regenerated organobentonite and PLA $+5 \%$ regenerated organobentonite is faster than neat PLA While PLA $+0,5 \%$ regenerated organobentonite and PLA $+1 \%$ regenerated organobentonite have slower biodegradation rate compared to neat PLA up to 30 days biodegradation time. This is influenced by the amount of water absorbed in the nanocomposite. The hydroxyl group will hydrolyze the PLA matrix after absorbing water from the compost [18]. In addition, water can facilitate the penetration of microorganisms into the nanocomposite [19] and grow in nanocomposites, since the matrix becomes the main energy source of microorganisms [20]. In other words, the more water absorption will lead to the greater the microorganisms that strike to the surface of the polyester. However, at the biodegradation time over 30 days, PLA-nanocomposites have a greater percentage of weight loss compared to neat PLA. Based on research conducted by Ray [18], after one month of biodegradation the weight loss of nanocomposites increased sharply in PLA + 4\% C3C18-mmt weight compared to neat PLA. Because one month is a critical time to start hydrolysis heterogeneously.

\section{Conclusion}

In this study, regeneration SBE is conducted to remove oil and impurities. FTIR analyses show that oil can be successfully remove from SBE. Afterwards, regenerated SBE and commercial bentonite are modified using organic compound. The XRD pattern demonstrated that modification of regenerated SBE and commercial bentonite with octadecylamine increase the interlayer distance. Regenerated organobentonite and commercial organobentonite was applied on PLA matrix. The XRD analyses show that nanocomposite structure was partially exfoliated. Consequently, the mechanical properties increase with the addition of low clays composition. The tensile strength and elongation at break exhibit a maximum at $0.5 \%$ of the clays, $51.76 \mathrm{MPa}$ and $3.98 \%$ for regenerated organobentonite and $50.98 \mathrm{MPa}$ and $3.92 \%$ for commercial bentonite. Regenerated organobentonite and commercial organobentonite could increase water barrier of nanocomposite with the addition up to $1 \%$. In addition, the degradation of the nanocomposite enhances with the addition of regenerated organobentonite.

\section{Acknowledgement}

The authors would like to thank Lembaga Pengelola Dana Pendidikan (LPDP) for financial support on this research through LPDP scholarship.

\section{References}

[1] A A. Heydari, A. Merikhy, H. Eskandari, F. Ghahraman-rozegar, M. Ghamin, in: Adsorption of the Methylene Blue from Aqueous Solution by the Thermally Regenerated Spent Bleaching Earth, International Conference on Chemical, Environmental and Biological Sciences, Dubai (2015).

[2] P.L. Boey, S. Ganesan, G.P. Maniam, D.M.H. Ali, in Ultrasound aided in situ transesterification of crude palm oil adsorbed on spent bleaching clay, Energy Conversion and Management, Vol. 52 (2011), pp. 2081-2084. https://doi.org/10.1016/j.enconman.2010.12.013

[3] A.A. Al-Zahrani and M.A. Daous, in: Recycling of Spent Bleaching Clay and Oil Recovery, Trans IChemE, Vol 78 (2000), pp. 223-228.

[4] Y. Xi, Z. Ding, H. He, R.L. Frost, in: Structure of organoclays - An $\mathrm{X}$-Ray diffraction and thermogravimetric analysis study, Journal of Colloid and Interface Science, Vol. 277 (2004), pp. 116-120. https://doi.org/10.1016/j.jcis.2004.04.053.

[5] S.I. Pirani, P. Krishnamachari, R. Hashaikeh, in: Optimum loading level of nanoclay in PLA nanocomposites: Impact on the mechanical properties and glass transition temperature, Journal of Thermoplastic Composite Materials, Vol. 27 (11) (2014), pp. 1461-1478. https://doi.org/10.1177/0892705712473627.

[6] W.S. Chow, Y.Y. Leu, Z.A. Mohd Ishak, in: Water Absorption of Poly(lactic acid) Nanocomposites:Effects of Nanofillers and Maleate Rubbers, Polymer-Plastics Technology and Engineering, Vol. 53 (2014), pp. 858-863. https://doi.org/10.1080/03602559.2014.886054.

[7] M. Zimmermann, J. Leifeld, S. Abiven, M.W.I. Schmidt, J. Fuhrer, in: Sodium hypochlorite separates an older soil organic matter fraction than acid hydrolysis, Geoderma, Vol. 139 (2007), pp. 171-179. https://doi.org/10.1016/j.geoderma.2007.01.014. 
[8] Y-P. Huang, J.I. Chang, in: Biodiesel production from residual oils recovered from spent bleaching earth, Renewable Energy, Vol 35 (2010), pp. 269-274. https://doi.org/10.1016/j.renene.2009.07.014.

[9] M. Mana, M.S. Ouali, L.C. de Menorval, J.J. Zajac, C. Charnay, in Regeneration of spent bleaching earth by treatment with cethyltrimethylammonium bromide for application in elimination of acid dye, Chemical Engineering Journal, Vol. 174 (2011), pp. 275-280 https://doi.org/10.1016/j.cej.2011.09.026.

[10] A. Giannakas, C.G. Spanos, N. Kourkoumelis, T. Vaimakis, A Ladavos, in: Prepration, characterization and water barrier properties of PL/organo-montmorillonite nanocomposites, European Polymer Journal, Vol. 44 (2008), pp. 3915-3921. https://doi.org/10.1016/j.eurpolymj.2008.10.001

[11] J-H. Chang, Y.U. An, G.S. Sur, in: Poly (lactic acid) Nanocomposite with Various Organoclays. I. Thermomechanical Properties, Morphology, and Gas Permeability, Journal of Polymer Science: Part B Polymer Physics, Vol 42 (2003), pp. 94-103. https://doi.org/10.1002/polb.10349.

[12] A. O. Ogah, K. R. Englund, in: Thermal, Mechanical, and Rheolog ical Properties of Agro Fiber Fill High Density Polyethylene Biocomposites, International Journal of Chemistry and Materials Research, Vol 4 (2016), pp. 10-21. https://doi.org/10.18488/journal.64/2016.4.2/64.2.10.21

[13] L. Zaidi, S. Bruzaud, A. Bourmaud, P. Mederic, M. Kaci, in: Relationship Between Structure and Rheological, Mechanical and Thermal Properties of Polylactide/Cloisite 30B Nanocomposites, Journal of Applied Polymer Science, Vol 116 (2010), pp. 1357-1365

[14] S.M. Lai, S.H. Wu, G.G. Lin, T.M. Don, in: Unusual mechanical properties of melt-blended poly(lactic acid) (PLA)/clay nanocomposites, European Polymer Journal, Vol. 52 (2014), pp. 193-206. https://doi.org/10.1016/j.eurpolymj.2013.12.012.

[15] J.C.H. Lai, F.R. Rahman, S. Hamdan, in: Comparative studies of thermo-mechanical and morphological properties of polylactic acid/fumed silica/clay (1.28E) and polylactic acid/fumed silica/clay (1.34TCN) nanocomposites, Polymer bulletin, Vol. 75 (2017), pp. 135-147. https://doi.org/10.1007/s00289-017-2025-z.

[16] F. Ma, X. Lu, Z. Wang, Z. Sun, F. Zhang, Y. Zheng, in: Nanocomposites of poly(L-lactide) and surface modified magnesia nanoparticles: Fabrication, mechanical property and biodegradability, Journal of Physics and Chemistry of Solids, Vol. 72 (2011), pp. 111-116. https://doi.org/10.1016/j.jpcs.2010.11.008

[17] R. Ollier, E. Rodriguez, V. Alvarez, in: Unsaturated polyester/bentonite nanocomposites: Influence of clay modification on final performance, Composites, Part A Vol. 48 (2013), pp.137-143. https://doi.org/10.1016/j.compositesa.2013.01.005.

[18] S.S. Ray, K. Yamada, M. Okamoto, K. Ueda, in: Control of Biodegradability of Polylactide via Nanocomposite Technology, Macromolecular Materials and Engineering, Vol. 288 (2003), pp. 203-208. https://doi.org/10.1002/mame.200390013.

[19] G.H. Yew, A.M. Mohd Yusof, Z.A. Mohd Ishak, U.S. Ishiaku, in Water absorption and enzymatic degradation of poly(lactic acid)/rice starch composites, Polymer Degradation and Stability, Vol. 90 (2005), pp. 488-500. https://doi.org/10.1016/j.polymdegradstab.2005.04.006.

[20] D.N. Bikiaris, in: Nanocomposites of aliphatic polyesters: An overview of the effect of different nanofillers on enzymatic hydrolysis and biodegradation of polyesters, Polymer Degradation, and Stability, Vol. $98 \quad$ (2013) ， pp. 1908-1928. https://doi.org/10.1016/j.polymdegradstab.2013.05.016. 